\title{
Recent advance in phase transition of vanadium oxide based solar reflectors and the fabrication progress
}

\author{
Golsa Mirbagheri ${ }^{1}$, David T. Crouse ${ }^{2}$, Chee-Keong $\operatorname{Tan}^{2}$ \\ Duke University Pratt School of Engineering ${ }^{1}$ \\ Computer and Electrical Department of Clarkson University ${ }^{2}$
}

Submitted in SPIE Photonics West OPTO in San Francisco/CA, US. January 2022

\begin{abstract}
ABSTARCT
Vanadium dioxide $\left(\mathrm{VO}_{2}\right)$ as a phase-change material controls the transferred heat during phase transition process between metal and insulator states. At temperature above $68^{\circ} \mathrm{C}$, the rutile structure $\mathrm{VO}_{2}$ keeps the heat out and increases the IR radiation reflectivity, while at the lower temperature the monoclinic structure $\mathrm{VO}_{2}$ acts as the transparent material and increase the transmission radiation. In this paper, we first present the metal-insulator phase transition (MIT) of the $\mathrm{VO}_{2}$ in high and low temperatures. Then we simulate the meta-surface $\mathrm{VO}_{2}$ of metamaterial reflector by Ansys HFSS to show the emittance tunability $(\Delta \varepsilon)$ of the rutile and monoclinic phase of the $\mathrm{VO}_{2}$. In next section, we will review the recent progress in the deposition of thermochromic $\mathrm{VO}_{2}$ on glass and silicon substrate with modifying the pressure of sputtering gases and temperature of the substrate. Finally, we present the results of the in-situ sputtered $\mathrm{VO}_{\mathrm{x}}$ thin film on thick $\mathrm{SiO}_{2}$ substrate in different combination of oxygen and argon environment by $\mathrm{V}_{2} \mathrm{O}_{5} \operatorname{target}$ at temperature higher than $300^{\circ} \mathrm{C}$ and then, analyze it with $\mathrm{x}$-ray diffraction (XRD) method. The thermochromic $\mathrm{VO}_{2}$ based metamaterial structures open a new route to the passive energy-efficient optical solar reflector in the past few years.
\end{abstract}

Keywords: Nanofabrication, Phase Transition Metamaterial, $\mathrm{V}_{2} \mathrm{O}_{5}$ target, Optical Solar Reflector, Vanadium Oxide

\section{INTRODUCTION}

The reversible metal-insulator phase transition (MIT) of $\mathrm{VO}_{2}$ has gained enormous attention in thermal control system of spacecrafts recently. However, among other metamaterials great effort is still investigated to understand the MIT process. In this section we review the recent advance in MIT mechanism of $\mathrm{VO}_{2}$ and discuss the physical properties of the rutile and monoclinic structures. $\mathrm{V}-\mathrm{O}$ system is one of the most interesting materials with different compounds including $\mathrm{VO}, \mathrm{VO}_{2}, \mathrm{~V}_{2} \mathrm{O}_{3}, \mathrm{~V}_{3} \mathrm{O}_{5}$, etc. Some of these components show metal-insulator transition (MIT) with a big change in thermal, optical, or electrical properties. These special properties encouraged scientists to use the $\mathrm{V}-\mathrm{O}$ system in many optical applications and therefore, learn the phase transition process. Among all various types of $\mathrm{V}-\mathrm{O}$ system, $\mathrm{VO}_{2}$ is considered for the temperature phase change mechanism $[1,2,3]$. Today, great effort has been made to understand the MIT phase change mechanism on various $\mathrm{VO}_{2}$ morphologies acquired from different types of fabrication methods. $[4,5,6]$. Despite the great progress has been made in recent years, the phase transition is still an arguable mechanism. The rapid transition between rutile metallic phase and monoclinic insulator phase is followed by changes in the crystallographic and electrical properties of $\mathrm{VO}_{2}$, accomplished by switching and sensing applications [7].

The isolator behavior of $\mathrm{VO}_{2}$ with $3 \mathrm{~d}_{1}$ orbital occupancy in room temperature and, forming other isolator phases in specific temperatures, all make it hard to interpret the phase change properties. One explanation for this change can be described by Peierls mechanism and electron correlation technique, which address the lattice distortion and the band gap shift. On the other hand, in the $3 \mathrm{~d} t 2 \mathrm{~g}$-derived states of the vanadium, when $\mathrm{d}_{\|}$bands break into occupied

\footnotetext{
${ }^{1}$ Send correspondence to Golsa Mirbagheri

E-mail: gm226@duke.edu
} 
bonding and empty antibonding, the $\pi^{*}$ states get depopulated and their energy increase that leads to create the bandgap. Therefore, a bandgap is created between the $\mathrm{d}_{\mathrm{l}}$ and the $\pi^{*}$ bands, illustrated in Figure 1. However, bandgap disappear in rutile phase to allow reflection of radiations. Therefore, we explain the lattice structures and electron interaction to learn more about the transition process.

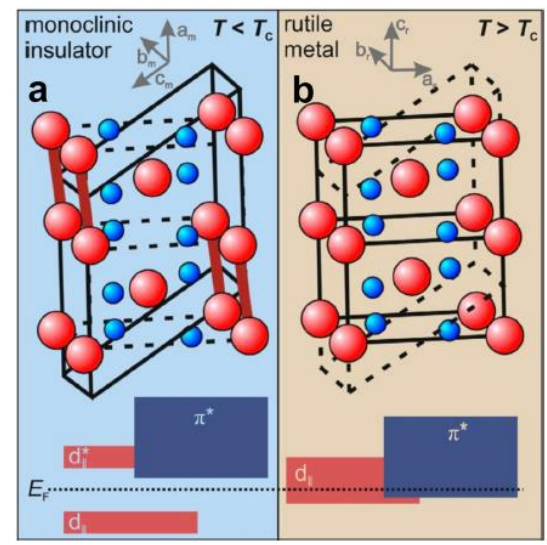

Figure 1. Bandgap in monoclinic (left) and rutile (right) phase of V [1]

The $\mathrm{VO}_{2}$ can grow in the form of different crystal structures, including monoclinic (M) and rutile (R) phases which show reversible phase change close to room temperature. During the phase change, the d-electrons of $\mathrm{V}$ atoms in the symmetrical structure join to the varying $\mathrm{V}-\mathrm{V}$ bonds in low symmetry monoclinic structure. There is an assumption that this $\mathrm{V}-\mathrm{V}$ localized structure derived from the high temperature delocalized phase and shows insulative properties. On the other hand, the conductivity property in the high temperature rutile phase is due to the fermi level between the $\pi^{*}$ band and the $\mathrm{d} \|$ band. While in M phase, the $\mathrm{d} \|$ band split to two parts, make a gap between $\mathrm{d} \|$ band and the $\pi^{*}$ band where Fermi level falls into that and lead to $\mathrm{VO}_{2}$ to be insulative. However, this theory is no clarified yet, since some research show that lattice distortion is not the only reason for MIT phase transition. One hypothesis is that there are other phases rather than $\mathrm{M}$, at the low temperature. With the help of doping, electron injection or stress effect, different phases of $\mathrm{VO}_{2}$ like $\mathrm{M} 2$ monoclinic, triclinic $\mathrm{VO}_{2}(\mathrm{~T})$ or other metastable monoclinic metal phases are discovered, which indicated that $\mathrm{V}-\mathrm{V}$ bond interactions is not the necessary step to open an insulating gap [1, 8, 9, 10]. Studying the transition phase of thermochromic $\mathrm{VO}_{2}$ makes a new path to understand the correlation effects of other thermal sensors $[11,12,13]$.
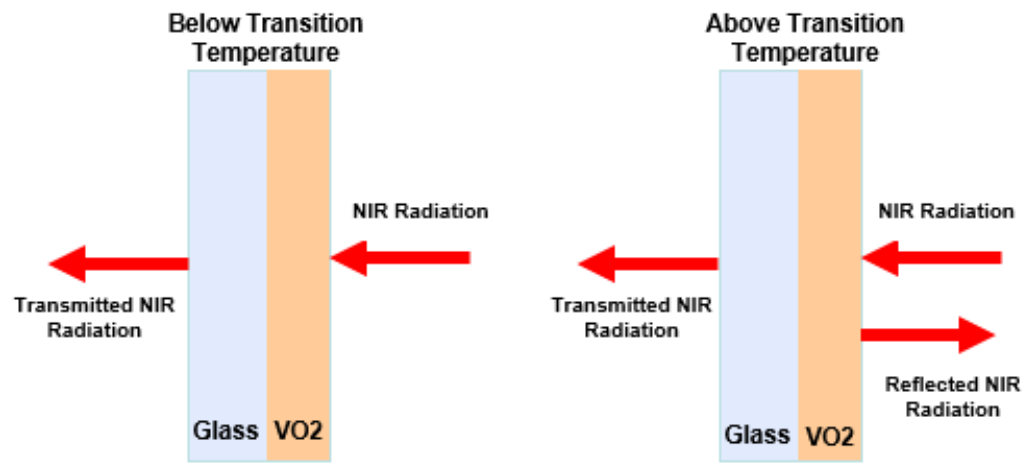

Figure 2. Vanadium dioxide semiconductor (left) to metal (right) phase transition at $68^{\circ} \mathrm{C}$ shows change in infrared reflectivity

As a thermochromic material, $\mathrm{VO}_{2}$ goes through semiconductor to metal phase transition at the specific temperature of $68^{\circ} \mathrm{C}$ which makes the change in infrared reflectivity, as shown in Figure 2. The transmission radiation changes with temperature and thickness of the $\mathrm{VO}_{2}$ material, which is demonstrated in Figure 3. The broadest extensive hysteresis transition belongs to the thickest $\mathrm{VO}_{2}$ with $50 \mathrm{~nm}$. By increasing the temperature above $68{ }^{\circ} \mathrm{C}$ at wavelength 
of $2 \mu \mathrm{m}$, the material keeps the heat out and IR radiation reflection increased since little radiation is transmitted into. To manipulate the transition temperature of the $\mathrm{VO}_{2}$ film different method were introduces including the adding various dopants, using multiple layers, or size effectiveness of $\mathrm{VO}_{2}$ lattice $[14,15,16,17]$.

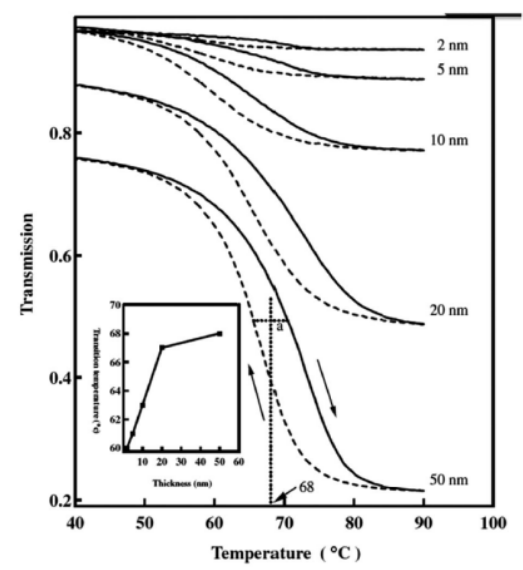

Figure 3. Transmission hysteresis loops for different thickness of $\mathrm{VO}_{2}$ thin film at wavelength $2 \mu \mathrm{m}$ [14]

\section{NUMERICAL SIMULATION OF FILTER}

In [18], the optical solar reflector (OSR) composed of plasmonic $\mathrm{VO}_{2}$ meta-surface is introduced to control the temperature of the satellite devices. The grating thermochromic $\mathrm{VO}_{2}$ in the OSR filter improve the absorption $(\alpha)$ and emittance tunability $\Delta \varepsilon$ with the help of plasmonic and thermochromic properties of $\mathrm{VO}_{2}$. This leads to higher absorption of the structure in higher temperature and lower absorption in temperature below the critical level. The smart meta-surface reflector shows higher tunability $\Delta \varepsilon$ at lower absorptance in comparison with the planar thin film design [19]. The OSR reflects the radiation of the sun and dissipates the thermal spectrum of onboard instruments to reduce the solar absorption and keep down the thermal fluctuation of the satellite. In contrast with active systems, the smart passive systems keep the heat at low temperature (low emittance) and dissipates extra heat at high temperature (high emittance) to keep the temperature at optimal ranges. This makes the passive systems cost and energy effective with lower weight. In passive thermal control structures, thermochromic $\mathrm{VO}_{2}$ works as a reflector and shows semiconductor to metal phase change at specific temperature $68 \mathrm{C}$ with high tunability of emittance. The critical temperature can be manipulated by doping or defect engineering methods to be near room temperature. The performance of the passive smart system can be explained by the dynamic emittance tunability of $\Delta \varepsilon=\varepsilon_{\text {hot }}-\varepsilon_{\text {cold }} . \mathrm{VO}_{2}$ based metamaterials exhibits phase transmission on plasmonic effects that shows higher absorption in metallic state and lower emittance in monoclinic phase, applicable over a wide range from visible and NIR to MWIR.

The insulator $\mathrm{SiO}_{2}$ in [18] is sandwiched between the meta-surface $\mathrm{VO}_{2}$ and aluminum reflector, shown in Figure 4, makes the destructive interference effect to improve the blackbody spectrum absorption and high tunability $\Delta \varepsilon$. The $\mathrm{Al}_{2} \mathrm{O}_{3}$ layer is considered as adhesion material.

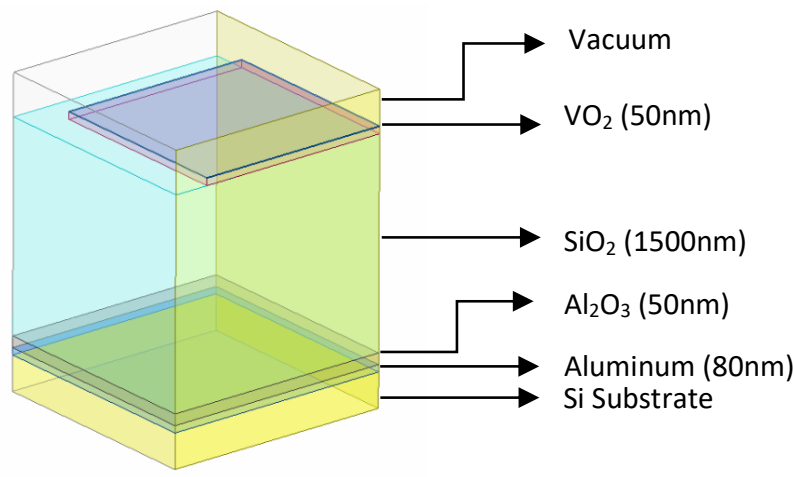

Figure 4. $\mathrm{VO}_{2}$ based OSR Schematic Simulated in HFSS 
The proposed structure is composed of the array of metasurface $\mathrm{VO}_{2}$ in the shape of the square grating and simulated by Ansys HFSS, demonstrated in Figure 4. The absorption infrared spectra of the monoclinic grating $\mathrm{VO}_{2}$ with grating squares size $2.8 \mu \mathrm{m}$ and different gaps between grating square changes from $3.3-4.35 \mu \mathrm{m}$ at temperature $30^{\circ} \mathrm{C}$ is low at $5-7 \mu \mathrm{m}$ and $12-18 \mu \mathrm{m}$ which is illustrated in Figure 5.

(a)

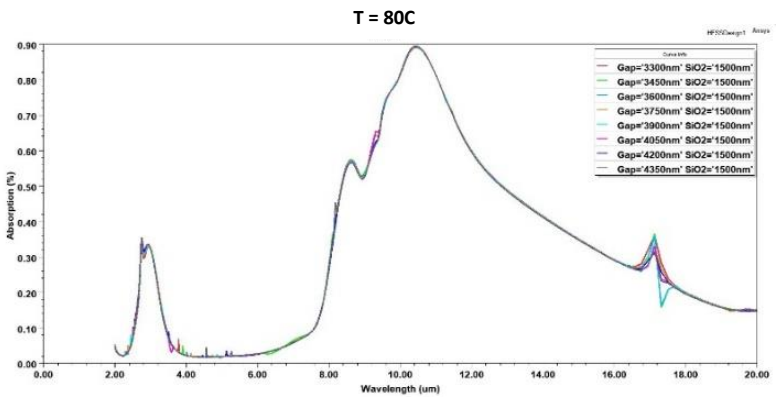

(b)

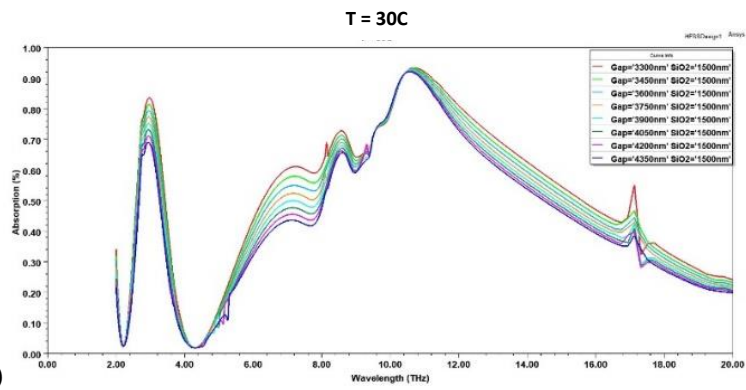

Absorption of Rutile and Monoclinic Structures

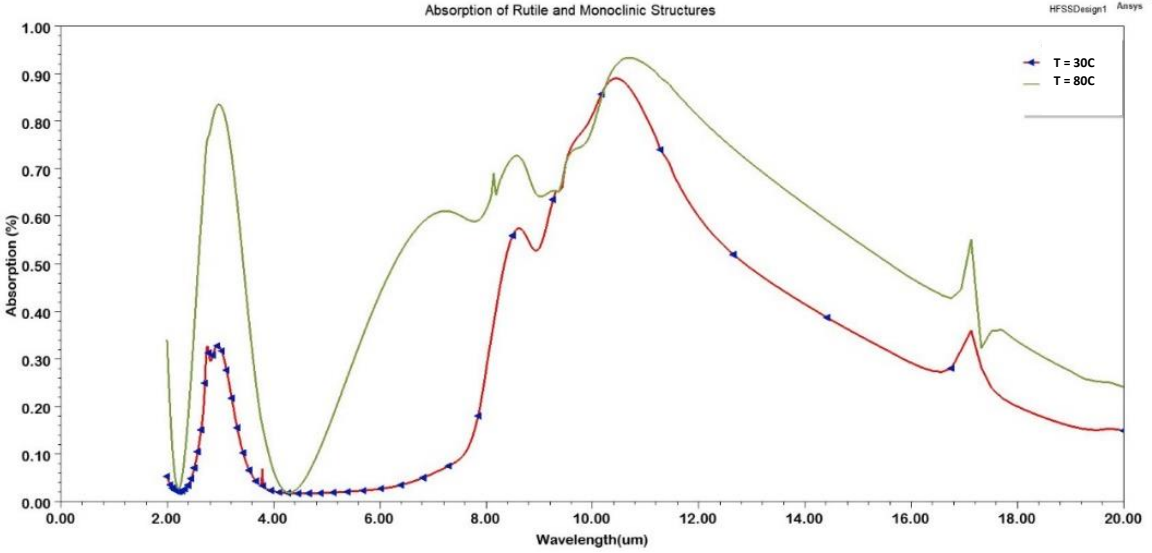

(c)

Figure 5. Absorption of meta surface $\mathrm{VO}_{2}$ at $30^{\circ} \mathrm{C}$ (a) and at $80^{\circ} \mathrm{C} \mathrm{(b)}$. Comparison of absorption of meta surface $\mathrm{VO}_{2}$ between two rutile and monoclinic structures of grating $\mathrm{VO}_{2}$ based metamaterial structure (c)

The emittance of a reflector is described in Eq. 1 as the average emittance weighted by blackbody spectrum at temperature $(\mathrm{T})$.

$$
\varepsilon=\frac{\int(1-\mathrm{R}(\lambda)) \mathrm{B}(\lambda, \mathrm{T}) \mathrm{d} \lambda}{\mathrm{B}(\lambda, \mathrm{T}) \mathrm{d} \lambda}
$$

Using $\mathrm{Eq} 1$, the emittance of the meta-surface $\mathrm{VO}_{2}$ with low-emissivity dielectric spacer in high and low temperature is calculated by the measuring the reflection spectra from FTIR method, as shown in Figure 6 (a). Therefore, it's not hard to find the emittance tunability $\Delta \varepsilon$ of the meta-surface $\mathrm{VO}_{2}$ at the peak of the blackbody spectrum, which is plotted in Figure 6 (b). The latter shows that by increasing the gap size between features (or decreasing the feature size of the grating $\mathrm{VO}_{2}$ ), maximum emittance tunability $\Delta \varepsilon$ improved about $\% 30$ in comparison with the planar film of $\mathrm{VO}_{2}$. 

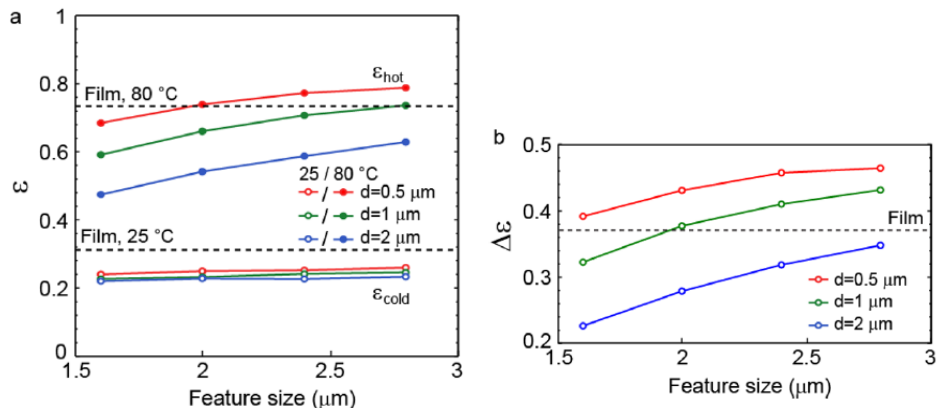

Figure 6. Measured emittance (left) and emittance tunability (right) of planar film (dash line) and meta-surface $\mathrm{VO}_{2}$ for high and low temperatures [18]

\section{REVIEW OF RECENT VO $\mathrm{V}_{2}$ DEPOSITION WORKS}

In the recent years, different methods were advised to sputter vanadium films [20, 21, 22]. In order to make thermochromic $\mathrm{VO}_{2}$ of metamaterial structures, we review some deposition approaches with the help of modifying the pressure of gases and temperature of the substrate [23, 24,25]. One method is to sputter thin film with vanadium target and then oxidized it in high temperature annealing environment at temperature $300{ }^{\circ} \mathrm{C}$ or above. The other popular way is reactive sputtering deposition which is performed with the partial oxygen pressure $\% 0$ to $\% 20$ of the total pressure (argon/oxygen atmosphere) at $300-600{ }^{\circ} \mathrm{C}$ to create different mixtures of $\mathrm{VO}_{\mathrm{x}}\left(\mathrm{V}_{2} \mathrm{O}_{3}, \mathrm{~V}_{2} \mathrm{O}_{5}\right.$ or $\left.\mathrm{VO}_{2}\right)$ on the substrate. The films can be analyzed with XRD, atomic force microscopy and X-ray photon spectroscopy (XPS) methods, in addition to checking the color of different composition of $\mathrm{VO}_{\mathrm{x}}$ visually [26]. Furthermore, post annealing in $300{ }^{\circ} \mathrm{C}$ or higher is recommended to form various types of $\mathrm{VO}_{\mathrm{x}}$ in other works. In [23], different forms of $\mathrm{VO}_{\mathrm{x}}$ were deposited on substrate with RF magnetron deposition by $\mathrm{V}_{2} \mathrm{O}_{5}$ target at temperature 300 to $527^{\circ} \mathrm{C}$ without annealing process. At the oxygen partial pressure less than $10^{-33}$ in room temperature in RF magnet deposition process, the $\mathrm{VO}_{2}$ is the most stable phase of the other composition of $\mathrm{VO}_{\mathrm{x}}$ from the $\mathrm{V}_{2} \mathrm{O}_{5}$ target. The $\mathrm{VO}_{2}$ thin film deposited on the glass substrate at $125 \mathrm{~W}$ plasma power with the oxygen partial pressure changing from $0-20 \%$ of argon/oxygen for 100 minutes. Meanwhile, at the oxygen partial pressure higher than $10^{-29}, \mathrm{~V}_{2} \mathrm{O}_{5}$ grows on the substrate as shown in Figure $7[23,27,28]$.

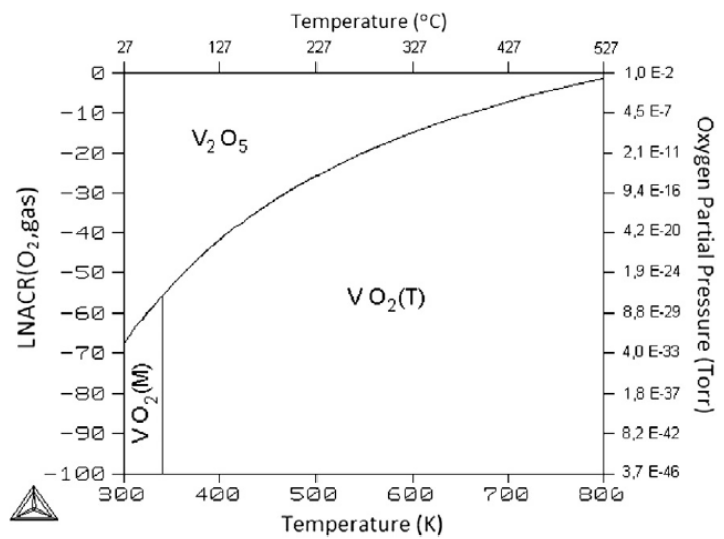

Figure 7. Monoclinic (M) and tetragonal ( $\mathrm{T}) \mathrm{VO}_{2}$ and $\mathrm{V}_{2} \mathrm{O}_{5}$ thin films growth from $\mathrm{V}_{2} \mathrm{O}_{5}$ target at partial oxygen pressures [23]

Reactive hydrogen is used for $\mathrm{Rf}$ sputtering of vanadium film with $\mathrm{V}_{2} \mathrm{O}_{5}$ target to reduce oxygen, whereas reactive oxygen is suggested for metallic vanadium or $\mathrm{V}_{2} \mathrm{O}_{3}$ target. The $\mathrm{V}_{2} \mathrm{O}_{3}$ target provides broader flow ratio during sputtering vanadium oxide, but it is more expensive than other two targets. Furthermore, metallic target gets oxidized during sputtering process, therefore, $\mathrm{V}_{2} \mathrm{O}_{5}$ is the most stable and best sputtering target to deposit rutile $\mathrm{VO}_{2}$. However, due to safety requirement, reactive oxygen is recommended with $\mathrm{V}_{2} \mathrm{O}_{5}$ target at higher temperature. In [24], rutile $\mathrm{VO}_{2}$ is deposited on fused silica glasses, $\mathrm{Si}$ or thick $\mathrm{SiO}_{2}$ on $\mathrm{Si}$ substrate from a $\mathrm{V}_{2} \mathrm{O}_{5}$ target by tuning substrate temperature and the oxygen flow rate. The temperature of substrate changed from 300 to $500{ }^{\circ} \mathrm{C}$ during the deposition with the total 
oxygen/argon pressure $12.5 \mathrm{mTorr}$ at the power of 60 or $120 \mathrm{~W}$ and the oxygen flow ratio $\left(\mathrm{R}_{\mathrm{fo}}\right)$ is adjusted between 0.042 to 0.1 based on Eq 2, where $\mathrm{f}$ is the flow rate of the gas.

$$
\mathrm{R}_{\mathrm{fo}}=\frac{\mathrm{fO} 2}{(\mathrm{fAr}+\mathrm{fO} 2)}
$$

The temperature of the substrate plays an important role for adjusting the oxygen component of the thin film. Figure 8 shows at lower temperature $300^{\circ} \mathrm{C}$, the $\mathrm{V}_{4} \mathrm{O}_{9}$ phase starts to grow on $\mathrm{Si}$ substrate. As temperature increases, $\mathrm{V}_{6} \mathrm{O}_{13}$ and meta-stable phase $\mathrm{VO}_{2}(\mathrm{~A})$ phases show at $\mathrm{R}_{\mathrm{fo}}=0.1$ due to less oxygen content of the films. Other phases with lower oxygen grow on the $\mathrm{Si}$ substrate when $\mathrm{R}_{\mathrm{fo}}$ is decreased. At higher temperature $500^{\circ} \mathrm{C}$, only rutile $\mathrm{VO}_{2}$ grows on the Si substrate with $\mathrm{R}_{\mathrm{fo}}$ between 0.06 and 0.042 in power $60 \mathrm{~W}$.

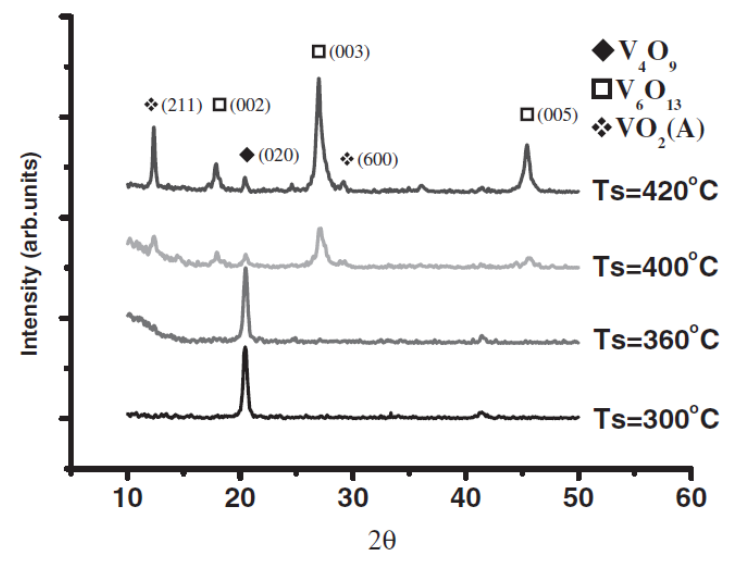

Figure 8. XRD result of thin films on Si substrate at different temperature from $300^{\circ} \mathrm{C}$ to $420^{\circ} \mathrm{C}$ for $\mathrm{R}_{\mathrm{fo}}=0.3$ [24]

Figure 9 shows that the increasing the temperature of substrate not only form the phases with lower oxygen, but also increase the average grain size of the deposited thin film.

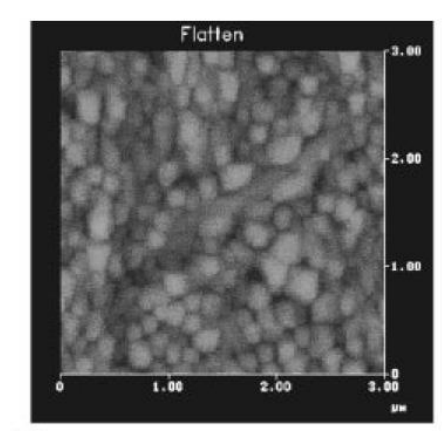

(a)

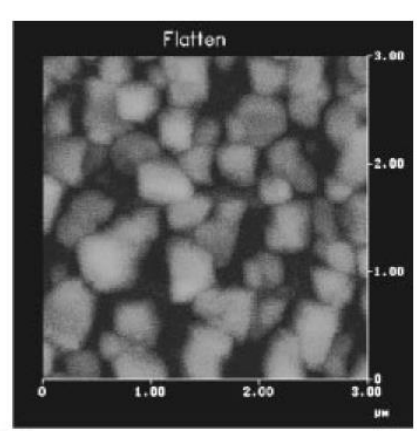

(b)

Figure 9. AFM results for grain sizes of mixed rutile $\mathrm{VO}_{2}$ and $\mathrm{VO}_{2}\left(\mathrm{~A}\right.$ ) phases at $\mathrm{T}=450^{\circ} \mathrm{C}$ (left) vs single phase rutile $\mathrm{VO}_{2}$ film at $\mathrm{T}=500^{\circ} \mathrm{C}$ (right) $[24]$

In [25], $\mathrm{VO}_{2}$ is sputtered from $\mathrm{V}_{2} \mathrm{O}_{5}$ target with reactive hydrogen $\left(2.5-10 \%\right.$ of $\mathrm{H}_{2}+\mathrm{Ar}$ ) at pressure $0.2 \mathrm{~Pa}$ and power $100 \mathrm{~W}$. After $30 \mathrm{~min}$ pre-sputtering, the temperature of the fused silica glass substrate kept at $400{ }^{\circ} \mathrm{C}$ to grow the $\mathrm{VO}_{2}$ smoothly. In [29], the deposited precursor vanadium on the $\mathrm{SiO}_{2} / \mathrm{Si}$ substrate with metal vanadium target is oxidized to $\mathrm{VO}_{2}$ in chamber at temperature $370-415^{\circ} \mathrm{C}$ and oxygen pressure 0.2 Torr. Furthermore, post annealing at $270{ }^{\circ} \mathrm{C}$ (better result at $450^{\circ} \mathrm{C}$ ) is an alternative method to oxidize the deposited vanadium to shape the $\mathrm{VO}_{2}$. However, the best results were related to the in-situ deposition immediately after deposition of precursor vanadium. In [30], the single (001) orientation orthorhombic metal vanadium is in situ deposited on sapphire, silicon, and glass substrates by RF sputtering with vanadium target in partial oxygen pressure $0-25 \%$ at temperature less than $100^{\circ} \mathrm{C}$. In [31], the deposited vanadium post-annealed at $530^{\circ} \mathrm{C}$ with an oxygen pressure between $14-18 \mathrm{~Pa}$ to not oxidize changing to 
$\mathrm{V}_{2} \mathrm{O}_{5}$. In [32], the phase transition of $\mathrm{VO}_{2}$ is improved by further post-annealing at $300^{\circ} \mathrm{C}$ in high-pressure oxygen 10 25 mTorr. The XRD result in Figure 10, shows thin film $\mathrm{VO}_{2}$ sputtered by pulsed laser deposition (PLD) method on thick oxide $\left(\mathrm{SiO}_{2} / \mathrm{Si}\right)$ substrate [33].

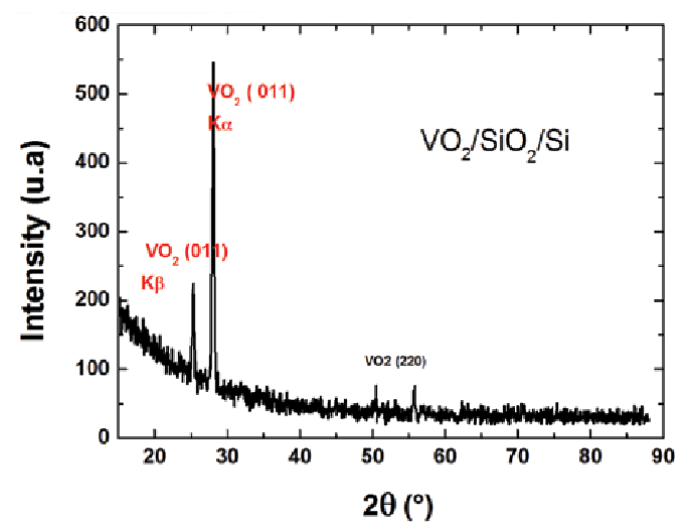

Figure 10. XRD results for $\mathrm{VO}_{2}$ film deposited on $\mathrm{SiO}_{2} / \mathrm{Si}$ substrate [33]

\section{EXPERIMENTAL RESULT}

In our work, we sputtered $50 \mathrm{~nm} \mathrm{VO}_{\mathrm{x}}$ film on $\mathrm{SiO}_{2} / \mathrm{Si}$ substrate by $\mathrm{V}_{2} \mathrm{O}_{5}$ target. The substrate is composed of $1.5 \mu \mathrm{m}$ thermal $\mathrm{SiO}_{2}$ deposited on silicon wafer by plasma-enhanced chemical vapor deposition (PECVD) method. During RF sputtering process, total gas pressure was kept at 12.5 mTorr for 2 hours deposition process. We did several sputtering tests for different temperature of substrate varied from $300^{\circ} \mathrm{C}$ to $500^{\circ} \mathrm{C}$ in-situ at a power of $120 \mathrm{~W}$ for different oxygen and argon flow ratio. The wafer height in the chamber held $20 \mathrm{~cm}$ from target. The surface of the thin film is characterized by $\mathrm{XRD}$ at temperatures $300^{\circ} \mathrm{C}, 400^{\circ} \mathrm{C}$ and $500^{\circ} \mathrm{C}$ in Figure 11, shows that for flow ratio $\mathrm{O}_{2}=$ $2 \mathrm{sccm}$ and $\operatorname{Ar}(\mathrm{P})=32 \mathrm{sccm}\left(\mathrm{R}_{\mathrm{fo}} 0.058\right)$, the deposited film on thick $\mathrm{SiO}_{2}$ is $\mathrm{V}_{2} \mathrm{O}_{3}$. We repeated the test for $\mathrm{R}_{\mathrm{fo}}$ between 0.042 to 0.06 , however the measured surface of the thin film by XRD technique showed $\mathrm{V}_{2} \mathrm{O}_{3}$ growth on the thick oxide substrate. The result did not change significantly after post-annealing process for partial oxygen pressure 100Torr at $300^{\circ} \mathrm{C}, 400^{\circ} \mathrm{C}$ and $500^{\circ} \mathrm{C}$. For the total volume of oxygen and nitrogen equal to $10 \mathrm{lit} / \mathrm{min}, \% 13$ oxygen $(1.3 \mathrm{lit} / \mathrm{min})$ and $\% 43$ nitrogen $(8.6 \mathrm{lit} / \mathrm{min})$ were considered to do post-anneal the sputter film about $10 \mathrm{minutes}$. In [34], the ALD deposited amorphous vanadium oxide crystallized in furnace annealing process in higher rate of nitrogen ratio (more than \%98) at temperature of $425^{\circ} \mathrm{C}$ and higher, as shown in Table $1[35,36,37,38]$. The gray rows in Table 1 show the successful annealing process of create polycrystalline stoichiometric $\mathrm{VO}_{2}$ phase.

\begin{tabular}{|c|c|c|c|c|c|c|c|c|}
\hline \multirow[b]{2}{*}{$\begin{array}{l}\text { Anneal } \\
\text { Temp }\end{array}$} & \multirow[b]{2}{*}{ Air } & \multicolumn{4}{|c|}{$\begin{array}{l}\text { Annealing time and gas ratio } \\
\text { under atmospheric pressure }\end{array}$} & \multicolumn{3}{|c|}{$\begin{array}{l}\text { Annealing time and gas ratio } \\
\text { under low vacuum }\left(10^{-2} \text { Torr }\right)\end{array}$} \\
\hline & & $\begin{array}{c}\mathrm{N}_{2} \\
(100 \%)\end{array}$ & $\begin{array}{l}98.78 \% \mathrm{~N}_{2} \\
+1.22 \% \mathrm{O}_{2}\end{array}$ & $\begin{array}{l}99 \% \mathrm{~N}_{2} \\
+1 \% \mathrm{O}_{2}\end{array}$ & $\begin{array}{l}98.5 \% \mathrm{~N}_{2} \\
+1.5 \% \mathrm{O}_{2}\end{array}$ & $\begin{array}{l}98.2 \% \mathrm{~N}_{2} \\
+1.8 \% \mathrm{O}_{2}\end{array}$ & $\begin{array}{l}99.4 \% \mathrm{~N}_{2} \\
+0.6 \% \mathrm{O}_{2}\end{array}$ & $\begin{array}{l}2.7 \times 10^{-2} \text { Torr } \\
(1 \mathrm{sccm} \mathrm{O})\end{array}$ \\
\hline $420^{\circ} \mathrm{C}$ & $30 \mathrm{~min}$ & & & & & & & \\
\hline $420^{\circ} \mathrm{C}$ & & $30 \mathrm{~min}$ & & & & & & \\
\hline $420^{\circ} \mathrm{C}$ & & & & $5 \min$ & & & & \\
\hline $420^{\circ} \mathrm{C}$ & & & & & $5 \mathrm{~min}$ & & & \\
\hline $420^{\circ} \mathrm{C}$ & & & & & & $10 \mathrm{~min}$ & & \\
\hline $420^{\circ} \mathrm{C}$ & & & & & & & $10 \mathrm{~min}$ & \\
\hline $425^{\circ} \mathrm{C}$ & & & $30 \mathrm{~min}$ & & & & & \\
\hline $430^{\circ} \mathrm{C}$ & & & & $5 \mathrm{~min}$ & & & & \\
\hline $450^{\circ} \mathrm{C}$ & $30 \mathrm{~min}$ & & & & & & & \\
\hline $450^{\circ} \mathrm{C}$ & & $30 \mathrm{~min}$ & & & & & & \\
\hline $450^{\circ} \mathrm{C}$ & & & & $30 \mathrm{~min}$ & & & & \\
\hline $450^{\circ} \mathrm{C}$ & & & & & $5 \mathrm{~min}$ & & & \\
\hline $450^{\circ} \mathrm{C}$ & & & & & & $10 \mathrm{~min}$ & & \\
\hline $450^{\circ} \mathrm{C}$ & & & & & & & $10 \mathrm{~min}$ & \\
\hline $500^{\circ} \mathrm{C}$ & & & & & & & & $60 \mathrm{~min}$ \\
\hline
\end{tabular}

Table 1. The furnace annealing result to crystallize the ALD deposited amorphous vanadium oxide film [34] 


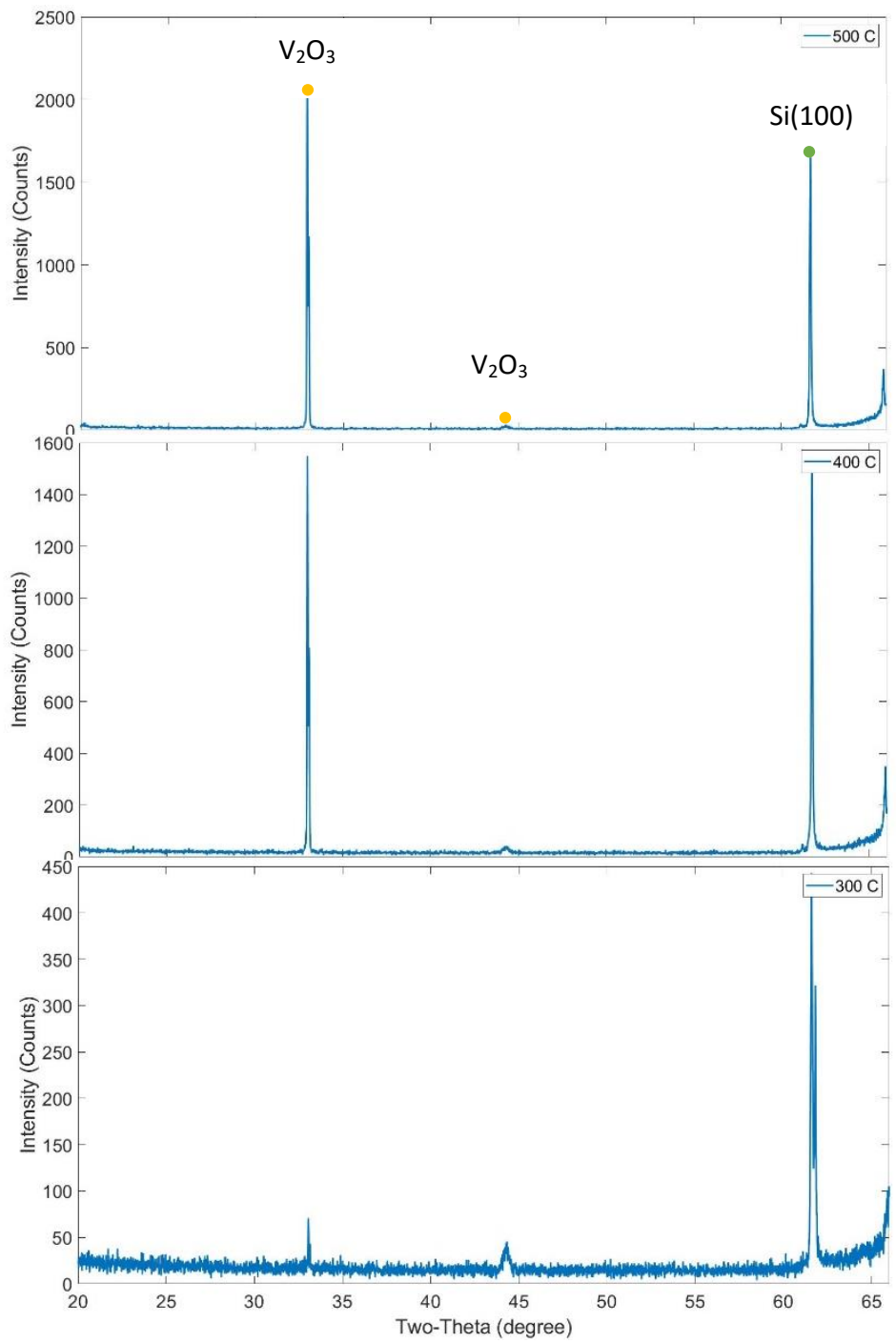

Figure 11. XRD result for sputtered film with Rfo 0.058 at temperature from $300^{\circ} \mathrm{C}$ (bottom), $400^{\circ} \mathrm{C}$ (middle) and $500^{\circ} \mathrm{C}$ (top)

\section{CONCLUSION}

In this article, the crystallographic and electrical properties of $\mathrm{VO}_{2}$ were reviewed to show the metal-insulator phase transition of the film at temperature $68^{\circ} \mathrm{C}$. The proposed $\mathrm{VO}_{2}$ based metamaterial structure was simulated with HFSS to demonstrate the emittance tunability $(\Delta \varepsilon)$ of rutile and monoclinic states of $\mathrm{VO}_{2}$. We summarized the recent progress in the in the deposition of thermochromic $\mathrm{VO}_{2}$ on glass and silicon substrate by focusing on changing the partial pressure of the oxygen and argon. Furthermore, we sputtered VOx by $\mathrm{V}_{2} \mathrm{O}_{5}$ target with Rfo between 0.042 to 0.6 at temperature $300^{\circ} \mathrm{C}$ and higher and measured it with XRD method, which resulted in forming the $\mathrm{V}_{2} \mathrm{O}_{3}$ on the thick oxide on silicon wafer. For future work, it is recommended to sputter the thin film VOx on sapphire or silicon substrate with $\mathrm{V}_{2} \mathrm{O}_{3}$, since $\mathrm{VO}_{2}$ grows smoothly on sapphire in comparison with the thick thermal $\mathrm{SiO}_{2}$. Thin films thermochromic vanadium dioxide is currently attracting much attention in areas such as microelectronics and spacecraft control systems for their electronic behaviors in MIT. 


\section{ACKNOWLEDGEMENT}

This work was performed in part at the Cornell NanoScale Facility, a member of the National Nanotechnology Coordinated Infrastructure (NNCI), which is supported by the National Science Foundation (Grant NNCI-2025233). Also, we appreciate the Cornell Center for Materials Research Shared Facilities which are supported through the NSF MRSEC program (DMR-1719875). We would like to thank the NSF Industry/University Cooperative Research Center for Metamaterials to support this project.

\section{REFERENCES}

[1] Shao Z., Cao X., Luo H. and Jin P., "Recent progress in the phase-transition mechanism and modulation of vanadium dioxide materials," NPG Asia Materials, vol. 10, pp. 581-605, (2018).

[2] Zhao B. and Zhang Z. M., "Design of Optical and Radiative Properties of Surfaces," Springer International Publishing AG, (2017).

[3] sitoga.eu, "VANADIUM DIOXIDE," PERFORMANCE, SILICON CMOS COMPATIBLE TRANSITION METAL OXIDE TECHNOLOGY FOR BOOSTING HIGHLY INTEGRATED PHOTONIC DEVICES WITH DISRUPTIVE, (2013).

[4] Mirbagheri G., Dunn K. J., Kosciolek D. J., Bendoym I. and Crouse D. T., "Hyperbolic metamaterial filter for angle-independent TM transmission in the infrared regime (Conference Presentation)," in SPIE Nanoscience + Engineering, San Diego, California, United States, vol. 103431U, (2017).

[5] Mirbagheri G., Crouse D. T., Dunn K. and Bendoym I., "Metamaterials based hyperspectral and multiwavelength filters for imaging applications," SPIE Defense + Commercial Sensing, vol. 109800A, (2019).

[6] Mirbagheri G., "Hyperbolic Metamaterial Filter for Angle-Independent TM-Transmission in Imaging Applications," Proquest, Potsdam, NY. US, (2020).

[7] Mirbagheri G. and Crouse D. T., " Design, fabrication, and spectral characterization of temperature-dependent liquid crystal-based metamaterial to tune dielectric metasurface resonances," SPIE Photonics West OPTO, (2022).

[8] Jin Y., "REACTIVE SPUTTER DEPOSITION OF VANADIUM, NICKEL, AND MOLYBDENUM OXIDE THIN FILMS FOR USE IN UNCOOLED INFRARED IMAGING," The Pennsylvania State University, The Graduate School, Department of Engineering Science and Mechanics, Philadeliphia, PA, (2014).

[9] Wu S.R., Lai K.L. and Wang C.M., "Passive temperature control based on a phase change metasurface," Scientific REPOrTS, vol. 8, no. 7684, (2018).

[10] Shelton D., Coffey K. and Boreman G. D., "Experimental demonstration of tunable phase in a thermochromic infrared-reflectarray metamaterial," OPTICS EXPRESS, vol. 18, no. 2, pp. 1330-1335, (2010).

[11] Ito K., Watari T., Nishikawa K., Yoshimoto H. and Iizuka H., "Inverting the thermal radiative contrast of vanadium dioxide by metasurfaces based on localized gap-plasmons," APL PHOTONICS, vol. 3, no. 086101 , (2018).

[12] Shin J.H., Moon K., Lee E. S., Lee I.M.and Park K. H., "Metal-VO2 hybrid grating structure for a terahertz active switchable linear polarizer," Nanotechnology, vol. 26 , no. 315203 , p. 7pp, (2015).

[13] Mirbagheri G. and Crouse D. T., " Design, fabrication, and spectral characterization of TM-polarized metamaterials-based narrowband infrared filter," SPIE Photonics West OPTO, (2022).

[14] Warwickab M. E. A. and Binions R., "Advances in thermochromic vanadium dioxide films," The Royal Society of Chemistry, p. 3275-3292, (2014).

[15] Eyert V., "VO2: A novel view from band theory," Physical Review Letters , (2011). 
[16] Kim H., Cheung K., R. C. .. Auyeung Y., Wilson D. E., Charipar K. M., Piqué A. and Charipar N. A., "VO2based switchable radiator for spacecraft thermal control," Scientific Reports, vol. 9, no. 11329, (2019).

[17] LEI L., LOU F., TAO K., HUANG H., CHENG X. and XU P., "Tunable and scalable broadband metamaterial absorber involving VO2-based phase transition," Photonics Research, vol. 7, no. 7, pp. 734-741, (2019).

[18] Sun K., Riedel C. A., Urbani A., Simeoni M., Mengali S., Zalkovskij M., Bilenberg B., Groot C. d. and Muskens O. L., "VO2 Thermochromic Metamaterial-Based Smart Optical Solar Reflector," ACS Photonics, vol. 5, no. 6, p. 2280-2286, (2018).

[19] Hamaoui G., Horny N., Gomez-Heredia C. L., Ramirez-Rincon J. A., Ordonez-Miranda J., Champeaux C., Dumas-Bouchiat F., Alvarado-Gil J. J., Ezzahri Y., Joulain K. and Chirtoc M., "Thermophysical characterisation of VO2 thin films hysteresis and its application in thermal rectification," Scientific Reports, vol. 9, no. 8728, (2019).

[20] Ho H.C., Lai Y.C., Chen K. and C.H. Thang Duy Dao H. N., "High quality thermochromic VO2 films prepared by magnetron sputtering using V2O5 target with in situ annealing," Applied Surface Science, vol. 495, no. 143436, (2019).

[21] Fangfang Song B. E. W. J., "Growth of ultra thin vanadium dioxide thin films using magnetron sputtering," Department of Physics, Applied Physics, Astronomy, Binghamton University - State University of New York, Binghamton, NY.

[22] Giannetta H. M. R., Calaza C., Fraigi L. and Fonseca L., "Vanadium Oxide Thin Films Obtained by Thermal Annealing of Layers Deposited by RF Magnetron Sputtering at Room Temperature," Licensee InTech, pp. 152168, (2017).

[23] Castro M. S. d., Ferreira C. L. and Avillez R. R. d., "Vanadium oxide thin films produced by magnetron sputtering from a V2O5 target at room temperature," Infrared Physics \& Technology, vol. 60 , p. 103-107, (2013).

[24] TSAI K.Y., CHIN T.S. and SHIEH H.P. D., "Properties of VO2 Films Sputter-Deposited from V2O5 Target," The Japan Society of Applied Physics, vol. 42, p. 4480-4483, (2003).

[25] SHIGESATO Y., ENOMOTO M. and ODAKA H., "Thermochromic VO2 Films Deposited by RF Magnetron Sputtering Using V2O3 or V2O5 Targets," The Japan Society of Applied Physics, vol. 39 , p. 6016-6024, (2000).

[26] CURRIE M., MASTRO M. A. and WHEELER V. D., "Characterizing the tunable refractive index of vanadium dioxide," OPTICAL MATERIALS EXPRESS, vol. 7, no. 5, pp. 1697-1707, (2017).

[27] Kusano E. and Theil J., "Deposition of vanadium oxide films by direct-current magnetron reactive," Journal of Vacuum Science \& Technology A Vacuum Surfaces and Films, vol. 6, no. 3, (1988).

[28] DAI K., LIAN J., MILLER M. J., WANG J., SHI Y., LIU Y., SONG H. and WANG X., "Optical properties of VO2 thin films deposited on different glass substrates," OPTICAL MATERIALS EXPRESS, vol. 9, no. 2, pp. 663-672, (2019).

[29] Gurvitch M., Luryi S., Polyakov A., Shabalov A., Dudley M., Wang G., Ge S. and Yakovlev V., "VO2 films with strong semiconductor to metal phase transition prepared by the precursor oxidation process," J. Appl. Phys. , vol. 102, p. 033504 ,(2007).

[30] Hansen S. D. and Aita C. R., "Low temperature reactive sputter deposition of vanadium oxide," Journal of Vacuum Science \& Technology, vol. 3, pp. 660-663, (1985).

[31] Liu X., Wang S.W., Chen F., Yu L. and Chen X., "Tuning phase transition temperature of VO2 thin films by annealing atmosphere," Journal of Physics D: Applied Physics, vol. 48 , no. 265104 , (2015).

[32] Song F. and B. E. W. Jr., "Growth control of the oxidation state in vanadium oxide thin films," Materials Science, (2016). 
[33] Hassein-Beya A. L. S., Lafanea S., Tahib H., Hassein-Bey A., Djafara A. A., Abdelli-Messacia S. and Benamard M. E. A., "Substrate Effect on Structural, Microstructural and Elemental Microcomposition of Vanadium Dioxide Thin Film," Modern Arabic Reviewof Fundamental \& Applied Physics, vol. 1, no. 2, pp. 24 -28, (2017).

[34] Tangirala M., Zhang K., Nminibapiel D., Pallem V., Dussarrat C., Cao W., Adam T. N., Johnson C. S., ElsayedAli H. E. and Baumgart H., "Physical Analysis of VO2 Films Grown by Atomic Layer Deposition and RF Magnetron Sputtering," ECS Journal of Solid State Science and Technology, vol. 3, no. 6, pp. N89-N94, (2014).

[35] Wang X., Guo Z., Gao Y. and Wang J., "Atomic layer deposition of vanadium oxide thin films from tetrakis(dimethylamino)vanadium precursor," JMR EARLY CAREER SCHOLARS IN MATERIALS SCIENCE ANNUAL ISSUE, vol. 32, no. 1, (2017).

[36] Currie M., Mastro M. A. and Wheeler V. D., "Atomic Layer Deposition of Vanadium Dioxide and a Temperature-dependent Optical Model," Journal of Visualized Experiments, vol. 135, no. e57103, (2018).

[37] Peter A. P., Toeller M., Adelmann C. and Schaekers M., "Process study and characterization of VO2 thin films synthesized by ALD using TEMAV and O3 precursors," ECS Journal of Solid State Science and Technology, vol. 1, no. 4, pp. 169-174, (2012).

[38] Mirbagheri G., "Hyperbolic Metamaterial Filter for Angle-Independent TM Transmission in the Infrared Regime," NanoMeter The Newsletter of the Cornell Nano Scale Facility, vol. 29, no. 2, p. 17, (2020). 